\title{
Reformas na educação profissional brasileira na década de 1990: consenso e hegemonia
}

\author{
The purpose of reforms in brazilian professional education in \\ the 1990s: \\ consensus and hegemony
}

\author{
Arão Davi OLIVEIRA ${ }^{1}$ \\ Celeida Maria Costa de SOUZA e SILVA²
}

\begin{abstract}
Resumo
Objetiva-se apresentar e discutir as propostas e interesses do empresariado nacional e dos organismos internacionais na reforma da educação profissional brasileira na década de 1990 . Essa é uma pesquisa qualitativa de abordagem documental e bibliográfica. Foram analisados documentos emanados por essas instituiçóes na década de 1990 à luz dos conceitos de estado, de Gramsci (1991), acumulação flexivel do capital, de Harvey (1992), e trabalho, de Marx (1971). Os documentos analisados promoveram um consenso no âmbito educativo nacional e serviram de referência para a proposição de reformas no sistema educacional brasileiro, que passou a priorizar uma formação geral, flexível e polivalente.
\end{abstract}

Palavras-chave: História da educação profissional. Políticas Públicas Educacionais. Acumulação Flexível do Capital.
Abstract

The objective is to present and discuss the proposals and interests of Brazilian businessmen and international organizations in the reform of Brazilian professional education in the 1990s. This is a qualitative research of documentary and bibliographic approach. The documents emanated by these institutions in the 1990s were analyzed in light of Gramsci's (1991) concepts of state; Harvey's, flexible capital accumulation (1992); and Marx's, work (1971). The documents analyzed promoted a consensus in the national educational context and served as a reference for the proposal of reforms in the Brazilian educational system that started to prioritize a general, flexible, polyvalent formation.

Keywords: History of professional education. Public Educational Policies. Flexible Accumulation of Capital.

1 Mestre em Educação, Doutorando em Educação do Programa de Pós-Graduação em Educação da Universidade Católica Dom Bosco (PPGE-UCDB). Bolsista de Doutorado da Coordenação de Aperfeiçoamento de Pessoal de Nível Superior (CAPES). Membro do Grupo de Pesquisa Políticas de Formação e Trabalho Docente na Educação Básica, vinculado ao PPGE/UCDB/MS, e do Grupo de Pesquisa Políticas Públicas Educacionais no âmbito da Educação Básica, vinculado ao PPGE/UCB/DF. Endereço profissional: Av. Tamandaré, 6000, Bloco D - Jardim Seminário - Campo Grande/MS. Cep. 79117-900, Tel. (67) 3312.3597, E-mail:<adodavi@gmail.com>.

2 Doutora em Educação. Pós-Doutoranda no Instituto de Educaçáo da Universidade Federal de Mato Grosso (UFMT). Docente do Programa de Pós-Graduação em Educação da Universidade Católica Dom Bosco (PPGE-UCDB). Coordenadora do Grupo de Pesquisa Políticas de Formação e Trabalho Docente na Educação Básica, vinculado ao PPGE/UCDB/MS, e do Grupo de Pesquisa Políticas Públicas Educacionais no âmbito da Educação Básica, vinculado ao PPGE/UCB/DF. Endereço profissional: Av. Tamandaré, 6000, Bloco D - Jardim Seminário - Campo Grande/MS. Cep. 79117-900, Tel. (67) 3312.3597. E-mail: <celeidams@uol.com.br>.

\begin{tabular}{|l|l|l|l|l|l|} 
R. Educ. Públ. & Cuiabá & v. 28 & n. 67 & p. 169-191 & jan./abr. 2019
\end{tabular}




\section{Introdução}

Este trabalho se assenta no campo da história das políticas educacionais brasileiras e oferece uma discussão sobre os interesses de organismos internacionais e grupo de empresários nacionais em estimular a reforma do sistema educativo brasileiro, em específico, da educação profissional na década de 1990. Com intuito de entender a formação do consenso que dominou as discussóes acerca das políticas educacionais brasileiras na década de 1990, focamos nossos estudos na Conferência Mundial de Educação para Todos, realizada em Jomtien (1990); no Relatório de Jacques Delors, em Educação: um tesouro a descobrir (DELORS, 1998); no documento Educação Básica e Formação Profissional: uma visão dos empresários (EBFP), publicado pela Confederação Nacional da Indústria (CNI), em 1993, e no documento Prioridades e Estratégias para a Educação, publicado pelo Banco Mundial, em 1995. Avaliamos que as citadas obras fazem parte de aparatos hegemônicos de dominação capitalista.

Os documentos aqui estudados estâo intimamente ligados ao incentivo de uma formação educacional voltada para maximizar a produtividade, pelo investimento no capital humano. A alusão a esses documentos internacionais torna-se importante, porque serve de base para a implementação de reformas no sistema educativo de países em desenvolvimento na América Latina e Caribe, a chamada cartilha neoliberal. No caso dos documentos emanados pela CNI, destacamos Educação básica e formação profissional: uma visão dos empresários (EBFP), pois o seu conteúdo traz inovaçôes em relação às reformas educacionais voltadas às demandas da produção flexível no Brasil.

O que se vê na década de 1990, é a adoção, por parte do Banco Mundial, das conclusóes da Conferência Internacional de Educação para Todos, realizada em Jomtien em 1990, a qual se tornou base para a elaboração de suas diretrizes políticas para as próximas décadas, culminando, em 1995, com a publicação do documento Prioridades y Estratégias para La Educación, que foi uma análise sobre a educaçáo que estabeleceu como prioridade e estratégia a celeridade dos países para reformarem seus sistemas educacionais, visando à universalização da educação e ao aumento da qualidade e equidade, com objetivo de vincular a educação às demandas de uma economia marcada por uma produção flexível. Nesse sentido, afirma que: "Em primeiro lugar, a educação deve ser concebida para satisfazer a crescente demanda por parte da economia, de trabalhadores adaptáveis, capazes de adquirir facilmente novos conhecimentos." (BANCO MUNDIAL, 1995, p. 7).

O Banco Mundial tornou-se, nos últimos anos, o organismo internacional de maior visibilidade no cenário educacional global. E, em grande parte, ocupando 
o espaço tradicionalmente atribuído à Organização para a Educação, à Ciência e à Cultura das Naçôes Unidas (UNESCO), agência da Organização das Naçóes Unidas (ONU), especializada em educação (TORRES, 1997, p. 3). Em nível internacional, esse Banco é a maior fonte de conselhos sobre a política educacional e fundos externos para esse setor.

Frigotto (2008, p. 10) diz que a educação tem um papel fundamental para a evoluçáo do capitalismo, promovendo desigualdades entre as naçóes e grupos sociais. Essa materialização ocorre por meio da educação profissional, internalizando nos seus frequentadores que, para eles conseguirem um emprego, precisam se tornar cidadáos produtivos, adaptados, adestrados e treinados. E, assim, a educação acaba sendo caracterizada "pelo viés economicista, fragmentário e tecnicista".

Nesta pesquisa, entendemos trabalho como categoria ontológica e econômica fundamental que não pode se reduzir a fator, assim como a educação também não pode ser a isso reduzida. Concebemos educação como uma prática social, uma atividade humana e histórica que se define no conjunto das relaçóes sociais, no embate dos grupos ou classes sociais, sendo forma específica de relação social.

Essa pesquisa é qualitativa, de abordagem documental e bibliográfica na qual utilizamos os conceitos de estado, de Gramsci (1991); acumulaçáo flexivel do capital, de Harvey (1992); e trabalho, de Marx (1971), para subsidiar as análises das categorias consenso, hegemonia, trabalho e educaçáo profissional.

\section{Acumulação flexível no Brasil e as propostas e influências do empresariado nacional e de organismos internacionais para educação profissional na década de 1990}

Entendemos que as diferentes articulaçóes entre a educação e o trabalho, a partir da década de 1970, se deram no contexto da fase de acumulação flexível do capital e que o Estado, no âmbito federal e estadual, tem mediado as demandas por formação de força de trabalho para o mercado requeridas por empresários dos diversos ramos da economia, assim como as demandas por formação técnica de nível médio pelos jovens. Essa mediação vem se dando por meio do sistema educacional de ensino, na modalidade Educação Profissional.

A passagem de um modelo de acumulação rígida taylorista/fordista para o modelo de acumulação flexível, com a introdução de novos modelos de produção exigiu um esforço "no sentido de adequar e submeter às forças de trabalho aos seus imperativos." (DEITOS, 2008, p. 242). O trabalhador foi moldado nos padróes 
fordista e taylorista, em que a produção em série e o controle das atividades por tempo não atendiam aos interesses de uma produçáo calcada nos requisitos da flexibilidade, exigindo, na concepção e execução da tarefa, a participação ativa do trabalhador no processo produtivo. Assim, o regime de acumulação flexível é um confronto direto com a rigidez do fordismo, conforme a seguir se explica:

Ela [a acumulação flexível] se apoia na flexibilidade dos processos de trabalho, dos produtos e dos padróes de consumo. Caracteriza-se pelo surgimento de setores de produção inteiramente novos, novas maneiras de fornecimento de serviços financeiros, novos mercados e, sobretudo, taxas altamente intensificadas de inovação comercial, tecnológica e organizacional. (HARVEY, 1992, p. 140).

A formação profissional entendida como necessária ao novo trabalhador supera a ideia da formação ligada exclusivamente ao posto de trabalho para atender uma formação mais generalista, que permita ao trabalhador adaptarse a diversas possibilidades de trabalho em ambientes mais flexíveis. Nesse sentido, organismos internacionais como o Banco Mundial (BM), que financiam projetos sociais em países da América Latina e Caribe, mostram textualmente a importância que atribuem à educação básica. Em 1995, esse organismo publica um documento intitulado Priorits and strategies for educación: a world bank sector rewiew, estabelecendo suas prioridades e estratégias para investimento na educação e apontando para uma formação mais polivalente, adaptável aos novos modelos de organização produtiva flexível.

A educaçáo básica proporciona o conhecimento, as habilidades e as atitudes essenciais para funcionar de maneira efetiva na sociedade sendo, portanto, uma prioridade em todo lugar. Esses atributos inclui um nível básico de competência em áreas gerais tais como as habilidades verbais, computacionais, comunicacionais e a resolução de problemas. Essas competências podem ser aplicadas a uma grande variedade de empregos e permitir as pessoas adquirir habilidades e conhecimentos específicos orientados para o trabalho, quando estiverem no local de trabalho. Em geral esse nível básico inclui cerca de oito anos de escolaridade. De fato, em alguns países, o primeiro ciclo de educação secundária está sendo combinado com a educação de primeiro grau para 
conformar uma etapa de educação obrigatória conhecida como "educação básica”. (BM, 1995, p. 63).

As novas normas de organização produtiva trouxeram novas exigências para a qualificação da força de trabalho. "A flexibilidade faz apelo ao savoir-faire e à competência da força de trabalho e, particularmente, à sua capacidade de dominar diferentes segmentos de um mesmo processo produtivo." (PAIVA, 1989, p. 21). A polivalência da força de trabalho torna-se o objetivo maior do sistema formativo requerido pelo capital, nesse sentido os organismos internacionais e os setores empresariais nacionais e internacionais se organizam para fazer valer a força do capital sobre o trabalho.

No ano de 1993, a CNI publica um documento intitulado Educação básica e formação profissional: uma visão dos empresários, em que atesta a importância que o sistema industrial dá ao capital humano, considerando-o como insumo básico para o desenvolvimento científico e tecnológico. Os empresários concluíram sobre a necessidade de se ajustar a formaçáo profissional, ou seja, de força de trabalho, pelos "avanços tecnológicos e de reorganização e gestão da produção, introduzido nos processos de trabalho na era da acumulação flexível." (IGNÁCIO, 2015, p. 116). Nesse documento, a CNI atesta:

Já não é possível que o indivíduo invista um grande período de tempo na educação e na formação profissional, com a intenção de adquirir um fundo de conhecimento ou de qualificação que seja suficiente para toda a sua carreira. A educação recebida pelos jovens deve ter uma base sólida, que facilite constantes aquisiçóes e atualização de conhecimento para o resto de sua vida produtiva. (CNI, 1993, p.10).

No documento EBFP, a CNI destaca que o modelo de investimento em automação para superar as deficiências do sistema educacional não atendia mais as necessidades do novo paradigma industrial baseado na produção flexível e flexibilização com ampla capacidade de adaptação às mudanças. "Isso significa que a integração com a contemporaneidade do mundo implica maior desenvolvimento e apropriação da ciência e tecnologia, enquanto principais instrumentos da dinâmica do sistema produtivo moderno." (CNI, 1993, p. 13). Ou seja, estava superada a estratégia de contratar operários menos qualificados para diminuir os custos com pessoal. A CNI destaca que "na nova economia a busca simultânea da produtividade e de altos padróes competitivos requer que as pessoas sejam tratadas como bens a serem incrementados para que se lhes possa adicionar valor, em oposição a custos que devem ser reduzidos." (CNI, 1993, p. 13). 
Essa estratégia de investimento na pessoa não é uma preocupação social dos empresários com seus funcionários, mas sim uma prática baseada na teoria do capital humano ${ }^{3}$, elaborada no contexto das teorias do desenvolvimento no cerne dos centros mais adiantados do capitalismo monopolista, que "disseminouse, e foi em passo acelerado absorvida pelos países do terceiro mundo", aponta Frigotto (2003, p.19). Muito se deve ao fato de o Banco Mundial exigir dos países tomadores de empréstimo que reformassem seus sistemas educativos, atendendo as sugestôes dos organismos internacionais para adaptar sua formação de força de trabalho aos novos ditames da fase de acumulação flexível do capital. O investimento no fator humano passa a significar um dos determinantes básicos para o aumento da produtividade e elemento de superação do atraso econômico. Do ponto de vista macroeconômico, constitui-se no fator explicativo das diferenças individuais de produtividade e de renda e, consequentemente, de mobilidade social (FRIGOTTO, 1984, p. 39).

Para Melo (2010, p. 65), deve-se analisar as aspiraçóes do empresariado industrial brasileiro constantes no documento EBFP articulado com um projeto societário funcionalista, no qual se prioriza a ênfase "na educaçáo básica, na formação de habilidades genéricas para os trabalhadores e a sua inserção como elemento para a competitividade", o que configura uma teoria do capital humano adaptada à fase de acumulação, produção e gestão flexível, nas quais "desigualdade se transforma em diferença", e as "classes sociais são substituídas pelo acento nas subjetividades" (2010, p. 65). As interpretaçóes de Melo (2010) apontam para a formação de um trabalhador preocupado apenas com seus interesses e arredio ao entendimento de classe, adaptável aos interesses da empresa. Nesse sentido, o projeto educativo do empresariado brasileiro se afasta de uma educação transformadora que possibilite à pessoa a superação de uma formação meramente instrumentalista para o atendimento das demandas por força de trabalho.

$\mathrm{O}$ interesse dos empresários industriais no sistema educativo nacional visa a alcançar padróes produtivos que garantam competitividade para a indústria; em consequência, com relaçáo ao fortalecimento da economia, à geração de empregos e ao desenvolvimento social; por essa ótica, os interesses da CNI vão além de "um projeto de uma classe e se transforma em projeto de toda a sociedade" (MELO, 2010, p. 65). Para garantir essa transformação na sociedade, os empresários defendem a universalização da educação básica, alinhada com as orientações originadas da Conferência de Jomtien/1990 e

3 Para o estudo da Teoria do Capital Humano é fundamental consultar a obra de Theodore Schultz, O valor econômico da educação (1963). No Brasil, Gaudêncio Frigotto em Educação e capitalismo real (2003). 
complementada pela educação profissional. Nesse documento, EBFP/1993 defende uma reforma curricular baseada em três eixos: "flexibilidade no saber; interdisciplinaridade do conhecimento; construção, pelo indivíduo, de uma visão globalizante dos processos tecnológicos, com ênfase na abstração, na apropriação de mecanismos lógicos e na transformação da maneira de pensar e construir conceitos." (CNI, 1993, p. 17).

A proposta dos empresários privilegia a aquisição de métodos de aprender em detrimento dos conteúdos a serem aprendidos. Interessante notar que um dos pilares da educação para o século XXI estabelecidos pela Organização das Naçóes Unidas para a Educaçáo, a Ciência e a Cultura (UNESCO) coaduna com os desejos do capital industrial, que é transformar a educaçáo básica em ferramenta que permita a pessoa adquirir capacidades de aprender métodos que possibilitem acompanhar as rápidas mudanças que a evolução tecnológica imprime ao mundo do trabalho. Ou seja, o aprender a aprender por toda vida, do qual decorre que "o trabalhador se capacite constantemente, e que sua formação básica seja direcionada para esta flexibilidade, que deverá incorporar para alavancar sua carreira." (MELO, 2010, p. 67).

A reforma curricular ocorrida na década de 1990, pautou-se numa formação humana baseada no saber fazer, que dispensa grandes conhecimentos teóricos, pois o currículo centralizou-se na noção de competência como modal da formação da força produtiva. Significa dizer que a prática se torna a referência do início e do fim do processo educativo, melhor adaptando o futuro trabalhador as novas formas de produção flexível. Esse modelo exige formação genérica e polivalente que insira o jovem no mundo da tecnologia e que consiga acompanhar as evoluçóes promovidas pelo avanço da tecnologia.

Sadri (2008, p. 267) defende que os avanços tecnológicos garantidos pelas intensas pesquisas promoveram uma espécie de "revolução do conhecimento". As reformas do currículo abarcadas nos PCNEM (1999, p. 15) indicam que o avanço da informática deve ser acompanhado pela educaçáo básica, pois "é possível afirmar que, nas próximas décadas, a educação vá se transformar mais rapidamente do que muitas outras, em função de uma nova compreensão teórica do papel da escola, estimulada pela incorporaçáo das novas tecnologias."

A reforma curricular pretendida pelos empresários tem vinculação com as orientaçôes da universalização da educação básica presentes na Declaração de Jomtien (1990), adotada pelo Banco Mundial na orientação das políticas educacionais dos países da América Latina e Caribe, e foram elencadas nos PCNEM; que, por sua vez, contemplam as orientaçóes do relatório de Jaques Delors (1998). Essa reforma prioriza a flexibilização do currículo, privilegia a subjetividade, a interdisciplinaridade e a transdisciplinaridade adaptada ao modelo 
flexível de produção. Percebe-se o afastamento da valorização dos conteúdos presentes no modelo taylorista/fordista.

As orientaçôes do relatório de Delors (1998), intitulado Educação: um tesouro a descobrir, aponta a necessidade da educação acompanhar as transformaçóes da sociedade, pois "não há dúvida de que a capacidade individual de ter acesso e de tratar a informação vai ser um fator determinante para a integração da pessoa, não só ao mundo do trabalho, mas também, no seu ambiente escolar e cultural." (DELORS, 1998, p. 190). Defende ainda a adoção de um sistema de alternância, em que o jovem frequenta a escola regular e, em outro período, o mundo do trabalho, nesse sentido afirma:

Para tentar instaurar uma sociedade em que cada um possa aprender e continue a aprender ao longo de toda a sua vida é preciso repensar as relaçôes entre os estabelecimentos de ensino e a sociedade, assim como a sequência dos diferentes níveis de ensino. No ensino, como na vida ativa, futuramente, os percursos serão necessariamente menos lineares, com períodos de estudo alternando com períodos de trabalho. Estes avanços e recuos devem ocupar um lugar cada vez mais importante na sociedade, graças a novas formas de certificação, a uma passagem mais fácil de um tipo ou de um nível de ensino para outro, e a separaçóes menos estritas entre educação e trabalho. (DELORS, 1998, p. 122-123).

Alguns fatores denotam a sujeição das políticas educacionais aos interesses do capital e, em determinados períodos, esses fatores são determinantes. "Nessa perspectiva a educação e a formação humana terão como sujeito definidor as necessidades, as demandas do processo de acumulação do capital sob as diferentes formas históricas de sociabilidade que assumir." (FRIGOTTO, 2003, p. 30). O que significa dizer que estão reguladas e subordinadas pela esfera privada e a sua reprodução.

O documento produzido e publicado pelo Banco Mundial, em 1990, Relatório sobre o Desenvolvimento Mundial, fez um levantamento da pobreza no mundo, traçando algumas medidas para atenuar essa condição, dentre as quais: deve-se "[...] ampliar e aperfeiçoar a educação primária e o atendimento médico básico" (BANCO MUNDIAL, 1990, p. 84).

Um dos motivos para se priorizar a educação básica, chamada de primária pelo Banco Mundial, parte do entendimento de que se investindo nessa etapa de ensino os governos reduzam a pobreza, "aumentando a produtividade do 
trabalho dos pobres, reduzindo a fecundidade, melhorando a saúde, e dota as pessoas de atitudes de que necessitam para participar plenamente na economia e na sociedade." (SHIROMA, MORAES, EVANGELISTA, 2002, p. 74-75). Significa dizer que investir em saúde e educação básica é investir em capital humano, ou seja, eleva os níveis de produção.

Sobre os resultados que a educação promove na produtividade das empresas e da necessidade de mudanças políticas nos países em desenvolvimento, o Banco Mundial destaca:

Educação aumenta a produtividade no mercado doméstico e permite adquirir mais informação; educação melhora a capacidade de aprender. Mas, para colher os benefícios de investimentos em educação precisa aumentar as oportunidades de aprendizagem produtivas através de inovações técnicas e mudanças nos regimes políticos e de mercado. (BANCO MUNDIAL, 1995, p. 28).

Analisando a proposta do Banco Mundial (1995) a partir do olhar de Torres (1997), podemos evidenciar os seguintes elementos: prioridade depositada sobre a educação básica; melhoria da qualidade e da eficácia da educação como eixo da reforma educativa; prioridade sobre os aspectos financeiros e administrativos da reforma educativa, dentre elas, descentralização e instituições escolares autônomas e responsáveis por seus resultados, porém os governos devem manter centralizadas apenas quatro funçóes: a de fixar padróes; a de facilitar os insumos que influenciam o rendimento escolar; a de adotar estratégias flexíveis para a aquisição e uso de tais insumos e a de monitorar o desempenho escolar, convocaçáo para uma maior participação dos pais e da comunidade nos assuntos escolares; impulso para o setor privado e organismos não governamentais como agentes ativos no terreno educativo, tanto nas decisóes como na implementação; mobilização e alocação eficaz de recursos adicionais para a educação como temas principais do diálogo e da negociação com os governos; adoção de um enfoque setorial; definição de políticas e estratégias baseadas na análise econômica.

Nesse sentido, o Brasil é obrigado, por ser financiado por esse organismo internacional, a "mobilizar as forças políticas necessárias para a produção do consenso, tendo em vista a realizaçáo do projeto internacional" (SHIROMA, MORAES, EVANGELISTA, 2002, p. 63), mobilizando, para isso, diversas representaçóes da sociedade civil e política para patrocinar essas reformas e alinhar o sistema educacional brasileiro com as recomendaçóes dos organismos internacionais. Especificamente para a educação profissional, o Banco Mundial (1995) defende que "a educação profissional dá melhores resultados quando conta 
com a participação direta do setor privado em sua administração, financiamento e direçáo". Isso indica o estreitamento dos laços do ensino com o setor produtivo, "fomentando os vínculos do setor público com o privado como a estratégia de base para a meta de equidade e eficiência no treinamento profissional." (SHIROMA, MORAES, EVANGELISTA, 2002, p. 62).

Interpretando essas contradiçóes e movimento histórico à luz de Harvey (1992, p. 178), "as provas de uma crescente flexibilidade (subcontratação, empregos temporários e atividades autônomas etc.) em todo o mundo capitalista são simplesmente demasiado claras." Para que essa flexibilidade seja produzida e reproduzida pelas escolas, fábricas, comércio, pela sociedade, faz-se necessário um convencimento ideológico, o qual acontece em correlação de forças entre as classes $^{4}$ para o estabelecimento de uma hegemonia dominante.

O aparato hegemônico dos organismos internacionais e do grupo organizado de empresários nacionais exerceu forte influência no sentido de estabelecer um consenso necessário para que a correlação de forças, em última instância, exercida pela sociedade jurídica fizesse prevalecer os interesses desse discurso hegemônico. Sobre o exercício da hegemonia Gramsci (2002), afirma que:

O critério metodológico sobre o qual deve se basear o próprio exame é esse: a supremacia de um grupo social se manifesta de dois modos, como "domínio" e como "direção intelectual e moral”. Um grupo social domina os grupos adversários, que visa a "liquidar" ou a submeter inclusive com força armada, e dirige grupos afins e aliados. Um grupo social pode e, aliás, deve ser dirigente já antes de conquistar o poder governamental (esta é uma das condições principais para a própria conquista do poder); depois, quando exerce o poder e mesmo se o mantém fortemente nas mãos, torna-se dominante mas deve continuar a ser também "dirigente". (GRAMSCI, 2002, p. 62-63).

Para Gramsci (2014), o convencimento ideológico se dá com a construção do consenso, o qual perpassa pela construção e manutenção da hegemonia. No caso citado, as fraçóes de classes burguesas, em certos momentos, incorporam os desejos democráticos das massas e dos organismos que vão difundir sua ideologia, a qual liga a estrutura e superestrutura, o que mantém o bloco histórico, que é

4 “[...] a classe que é a força material dominante da sociedade é, ao mesmo tempo, sua força espiritual. A classe que tem à sua disposição os meios de produção material dispóe, ao mesmo tempo, dos meios de produção espiritual, o que faz com que a ela sejam submetidas, ao mesmo tempo e em média, as ideias daqueles aos quais faltam os meios de produçáo espiritual.” (MARX, ENGELS, 2007, p. 47). 
"a identificação entre o conteúdo econômico-social [estrutura] e a forma éticopolítica [superestrutura].” (GRAMSCI, 2014, p. 308).

Ainda em Gramsci (2014), dizemos que a sociedade civil está ligada organicamente à sociedade política e são planos da superestrutura. No dizer de Gramsci:

[...] o que pode ser chamado de 'sociedade civil' (isto é, o conjunto de organismos designados vulgarmente como 'privados') e o da 'sociedade política' planos que correspondem, respectivamente, à função de 'hegemonia' que o grupo dominante exerce em toda a sociedade e àquela de 'domínio direto' ou de comando, que se expressa no Estado e no governo 'jurídico’. (GRAMSCI, 1987, p. 21).

Sob essa ótica, Gramsci estabelece sua concepção de Estado, como "todo o complexo de atividades práticas e teóricas com as quais a classe dirigente justifica e mantém não só o seu domínio, mas consegue obter o consentimento ativo dos governados." (GRAMSCI, 1991, p. 91). É sob essa ótica de Estado que percebemos e entendemos que o discurso hegemônico dos que defendiam uma reforma na educação profissional brasileira prevaleceu nessa década de 1990 .

Ainda sobre a hegemonia, Frigotto (2005) afirma que no contexto brasileiro a classe hegemônica é orientada pelas teorias neoliberais, planejadas para os países da América Latina e Caribe pelos Organismos Internacionais, destacadamente o $\mathrm{FMI}^{5}$, Banco Mundial e UNESCO ${ }^{6}$, que defendiam que a economia náo deveria ser regulada por políticas estatais e sim pelo mercado e as leis da demanda e da procura, da livre concorrência, da competição, do individualismo e da maior produtividade com o mínimo de custo.

No ano de 1996, finalmente foi sancionada a Lei Federal no 9.394, que estabelece as Diretrizes e Bases da Educação Nacional (LDBN), dispondo em seu Art. 39 que a "educação profissional, integrada às diferentes formas de educação, ao trabalho, à ciência e à tecnologia, conduz ao permanente desenvolvimento de aptidōes para a vida produtiva." (BRASIL, 1996). Essa concepção, advinda dos documentos legais em vigor, atribui uma nova identificação à educação profissional, marcada pela superação do preconceito social que a desvalorizava ${ }^{7}$.

5 Fundo Monetário Internacional.

6 Organização das Naçōes Unidas para a Educação, Ciência e Cultura.

7 Parecer CNE/CEB n. ${ }^{\circ}$ 16/99. Trata das Diretrizes Curriculares Nacionais para a Educaçáo Profissional de Nível Técnico. Disponível em: <http://webcache.googleusercontent.com/search?q=cache:d2g-jMENPVIJ:portal.mec. gov.br/setec/arquivos/pdf_legislacao/rede/legisla_rede_parecer1699.pdf $+\& c d=1 \& \mathrm{chl}=\mathrm{pt}-\mathrm{BR} \& \mathrm{ct}=\mathrm{clnk} \& \mathrm{gl}=\mathrm{br}>$. Acessado em 10 julho de 2015. 
Na LDBN, a Educação Profissional passa a integrar a Educação Básica, como modalidade do Ensino Médio. Para Bremer e Kuenzer (2012, p. 6), "nesta nova proposta, a partir do reconhecimento das relaçóes entre trabalho, ciência e cultura; desta forma, pelo menos no texto legal, a dualidade entre educação geral e formação profissional estaria superada."

No governo Fernando Henrique Cardoso (1995-2002), houve uma reformulação na educaçáo profissional por meio do Decreto no 2.208/1997, assentado na noção da pedagogia das competências. Esse Decreto separava a educação profissional do ensino propedêutico. Para Bremer e Kuenzer (2012, p. 6), isso se deve à "acentuada dualidade, a partir dos arranjos flexíveis de competências diferenciadas para atender a uma demanda de qualificação puxada pela demanda do sistema produtivo."

Para Frigotto, Ciavatta e Ramos (2012, p. 25), o primeiro projeto de LDBEN propunha uma "formação profissional integrada à formação geral nos seus múltiplos aspectos humanísticos e científico tecnológicos", o que se tornou inviável a partir do Decreto no 2.208/1997 e da Portaria do MEC no 646/1997, que regulamenta a implantação do disposto nos Artigos 39 a 42 da Lei Federal no 9.394/1996. Na visão desses autores, esses dispositivos, além de proibirem a almejada formação integrada, regulamentavam "formas fragmentadas e aligeiradas de educação profissional em função das alegadas necessidades do mercado. O que ocorreu também por iniciativa do Ministério do Trabalho e Emprego, por meio de sua política de formação profissional.” (FRIGOTTO, CIAVATTA, RAMOS, 2012, p. 25).

Coadunamos com Frigotto, Ciavatta e Ramos (2005, p. 49) quando defendem um Ensino Médio que ofereça u ma formação in tegral ou omnilateral "fundamentado em uma base comum e tendo como eixo estruturante o trabalho, a ciência, a tecnologia e a cultura, independentemente de ser ou não profissionalizante", pois esse modelo de ensino promove, em última instância, uma escola unitária, tendo em vista que a formação científica e cultural não ficam dissociadas do processo de ensino-aprendizagem, tampouco distingue uma escola para os filhos dos ricos e outra para os filhos dos pobres.

O entendimento de que uma formação integrada permite uma melhor relação do homem com a natureza, entendendo-a e transformando-a por meio do trabalho, nos dizeres de Saviani (2003), Frigotto, Ciavatta e Ramos (2005) advêm da proposta emancipatória de Marx (2010), para formar um novo entendimento de sociabilidade humana que vise a superar as injustiças e desigualdades decorrentes do processo de acumulação capitalista, assim como da sociedade de classes. Conforme Marx: 
[...] o homem se apropria de sua essência omnilateral de uma maneira omnilateral. Cada uma das suas relaçôes humanas com o mundo, ver, ouvir, cheirar, degustar, sentir, pensar, intuir, perceber, querer, ser ativo, amar, enfim todos os órgáos da sua individualidade, assim como os órgãos que são imediatamente em sua forma como órgãos comunitários. (MARX, 2010, p. 108).

O pensamento de formação integral defendido por Saviani (2003), Frigotto, Ciavatta e Ramos (2005) também decorre da teoria de Gramsci (2010) para a emancipação do homem por meio de uma escola unitária, que ofereça uma formação omnilateral. Nas palavras de Gramsci:

O advento da escola unitária significa o início de novas relaçóes entre o trabalho intelectual e trabalho industrial não apenas na escola, mas em toda vida social. O princípio unitário, por isso, irá se refletir em todos os organismos de cultura, transformando-os e emprestando-lhes um novo conteúdo. (GRAMSCI, 2010, p. 40).

Acreditamos que as políticas públicas de educação profissional e tecnológica (EPT) deveriam ser desenvolvidas nos moldes de uma formação omnilateral teorizada por Gramsci (2010) e Marx (2010). Coadunamos com Frigotto, Ciavatta e Ramos (2005), quando questionam:

Se a preparaçáo profissional no ensino médio é uma imposição da realidade, admitir legalmente essa necessidade é um problema ético. Não obstante, se o que se persegue não é somente atender a essa necessidade, mas mudar as condiçôes em que ela se constitui, é também uma obrigação ética e política, garantir que o ensino médio se desenvolva sobre uma base unitária para todos. Portanto, o ensino médio integrado ao ensino técnico, sob uma base unitária de formação geral, é uma condição necessária para se fazer a "travessia" para uma nova realidade. (FRIGOTTO, CIAVATTA, RAMOS, 2005, p. 49).

"Um projeto de ensino médio integrado ao ensino técnico, tendo como eixo o trabalho, a ciência e a cultura, deve buscar superar o histórico conflito existente em torno do papel da escola de formar para a cidadania ou para o trabalho produtivo." (RAMOS, 2012, p. 107). 
Nesse aspecto, observamos o avanço das relaçóes capitalistas de produção no seio do Estado, o que favoreceu a valorização do conhecimento técnico e científico, tornando a escola uma instituição voltada a formar para a cultura industrialista (GRAMSCI, 1991).

A correlação de forças entre as demandas dos trabalhadores por qualificação, assim como as demandas por trabalhadores qualificados para alimentar o sistema produtivo, pressiona o Estado a legislar. A legislação pode ser visualizada como um artifício; que, embora não responda de modo inequívoco às demandas sociais, resulta da correlação de forças que predominam em um contexto social e político.

Exemplo dessa correlação de forças é observado por Oliveira (2002), que destaca o posicionamento do Banco Mundial frente aos investimentos públicos em cursos técnicos na Rede Federal de Educação Profissional e Tecnológica, considerando-os muito dispendiosos. Essa autora afirma que "os custos do ensino médio integrado ao técnico, foram considerados muito altos para serem arcados pelo poder público.” (2002, p. 57). Os esforços federais para reduzir os custos com o Ensino Médio também foram imperativos para a efetivaçáo do Decreto $n^{\circ}$ 2.208/1997.

No dizer dessa autora:

É possível mesmo inferir que, mesmo não sendo a razão principal, a possibilidade de barateamento do ensino médio pode ter contribuído para a urgência atribuída pelo poder executivo atribuído a reforma da educação profissional, desrespeitando as discussóes que se realizavam no movimento dos trabalhadores dos CEFETs e demais escolas técnicas [...] (OLIVEIRA, 2002, p. 57-58).

O Decreto no 2.208/1997 regulamenta o parágrafo $2^{\circ}$ do Art. 36 e os Artigos 39 a 42 da LDBEN, Lei no 9.394/1996. Como já foi dito, separou o ensino técnico do propedêutico, o que significa dizer que a conquista de uma educação unitária aprovada na LDBEN n. 9.394/1996 já sofrera sua primeira mudança. Pela determinação do MEC, não poderiam mais ser ofertados cursos de Ensino Médio integrados à educação profissional.

No Art. $5^{\circ}$ do Decreto ${ }^{\circ}$ 2.208/1997, retoma-se a dualidade histórica da educação brasileira, o que em certa medida perpetua a divisão social do trabalho, visto que pela educação propedêutica, prepara-se para a intelectualidade, e pela educação profissional, prepara-se o jovem para o ingresso no mercado de trabalho. Textualmente, assevera: "A educação profissional que prepara o jovem para ingressar no mundo do trabalho, educação profissional de nível técnico terá organização curricular própria e independente do ensino médio, podendo ser oferecida de forma concomitante ou sequencial a este." (BRASIL, 1997). 
Kuenzer (2006, p. 887) destaca que o Decreto $n^{\circ} 2.208 / 1997$ significou o suporte jurídico necessário para a execução de um programa de formação profissional originado de um acordo entre Banco Mundial e o MEC, chamado Plano Nacional de Qualificação do Trabalhador (PLANFOR). Essa autora destaca que os investimentos do PLANFOR foram realizados em cursos de curta duraçáo que não agregam qualidade à educação.

Não temos a intenção aqui de analisar o PLANFOR, mas sim de percebermos como a proposta do Banco Mundial, de desvinculação da formação profissional com o Ensino Médio, foi atendida pelo Decreto n ${ }^{\circ} 2.208 / 1997$, e como ocorreu a priorização da qualificação profissional executada em instituiçóes privadas de ensino. "Os cursos rápidos, sem regulamentação, sem pré-requisitos de escolaridade e pagos, oferecidos no âmbito do PLANFOR, são uma forma precária de acesso à uma formação profissional para a maioria da classe trabalhadora." (MELO, 2010, p. 77). Isso foi possibilitado pelo texto do Art. $3^{\circ}$ do mesmo Decreto, que dividiu a educação profissional em três níveis, criando o nível básico, o qual não necessitaria de qualquer escolaridade prévia, como segue: "A educação profissional compreende os seguintes níveis: I - básico: destinado à qualificação, requalificação e reprofissionalização de trabalhadores, independente de escolaridade prévia; II técnico: [...]; III - tecnológico: [...]" (BRASIL, 1997).

Em consonância com a cartilha neoliberal, da qual os países da América Latina são caudatários, o governo de Fernando Henrique Cardoso (1995-2002) efetivou a descentralização da administraçáo com a reforma do aparelho institucional, igualmente em busca de eficiência na gestão da educação. Não por acaso foram efetivadas reformas, também, nos currículos do Ensino Médio e Profissional. Primeiro, foram as Diretrizes Curriculares Nacionais do Ensino Médio (DCNEM), estabelecidas pelo Parecer CNE/CEB n ${ }^{\circ}$ 15/1998; depois, as Diretrizes Curriculares Nacionais da Educação Profissional Técnica de Nível Médio (DCNEP), estabelecidas pelo Parecer CNE/CEB no 16/1999, ambas sob forte influência do relatório de Jaques Delors (1998), o qual aponta quatro supostos imperativos para a educaçáo, ou como consta no relatório, "quatro pilares da educação: aprender a conhecer, aprender a fazer, aprender a conviver e aprender a ser" (DELORS, 1998, ).

Para Ciavatta e Ramos (2012, p. 17), as DCNEM/1998 e as DCNEP/1999, "ambas baseadas em competências, tiveram como fundamento os princípios axiológicos expostos nas respectivas diretrizes, na verdade, uma releitura desses pilares." Nas DCNEM, o Art. $4^{\circ}$ do Parecer CNE/CEB no 15/1998, assevera que: "as propostas pedagógicas das escolas e os currículos constantes dessas propostas incluirão competências básicas, conteúdos e formas de tratamento dos conteúdos, previstas pelas finalidades do ensino médio estabelecidas pela lei." (BRASIL, 1998). Já na DCNEP/1999, Parecer no 16/1999, o modelo das competências torna-se mais explícito, como segue: 
As características atuais do setor produtivo tornam cada vez mais tênues as fronteiras entre práticas profissionais. Um técnico precisa ter competências para transitar com maior desenvoltura e atender às várias demandas de uma área profissional, não se restringindo a uma habilitação vinculada especificamente a um posto de trabalho. (BRASIL, 1999, p. 112).

O estímulo à polivalência expresso nas DCNEP/1999 visa a formar um novo perfil de trabalhador requerido pelas demandas do sistema de produção flexível, versadas nas recomendaçóes presentes nos documentos do Banco Mundial (1995) e CNI (1993).

Ainda explorando a ênfase no modelo de competências, consta no Parecer no 16/1999: "o mundo do trabalho está se alterando contínua e profundamente, pressupondo a superação das qualificaçóes restritas às exigências de postos delimitados, o que determina a emergência de um novo modelo de educação centrado em competências por área.” (BRASIL, 1999, p. 113).

Essa reforma na educação profissional reforça que “a principal finalidade da educação contemporânea seria a formação de personalidades flexíveis para a adaptação à realidade instável e incerta.” (CIAVATTA, RAMOS, 2012, p. 17). Percebe-se que o sistema capitalista promove sua reestruturação produtiva e submete os países de economia dependente às reformas que julgam necessárias para acompanhar a produção, distribuição e comercialização. Consequentemente, a reforma curricular no Brasil faz parte do processo de adaptação do seu sistema educativo à formação de força de trabalho flexível.

Desde as discussóes acerca do Projeto de Lei que deu origem à Lei no 9.394/1996, os representantes do empresariado vinham tencionando o Governo Federal para que a legislação educacional brasileira atendesse aos interesses do sistema produtivo que exigia uma formação mais flexível baseada no princípio das competências ${ }^{8}$. Como exemplo, a desvinculação da formação profissional da educação básica.

8 A qualificação tem sido tensionada pela noção de competência, em razão do enfraquecimento de suas dimensōes conceitual e social, em benefício da dimensão experimental. A primeira porque os saberes tácitos e sociais adquirem relevância diante dos saberes formais, cuja posse era normalmente atestada pelos diplomas. A segunda porque, em face da crise do emprego e da valorizaçáo de potencialidades individuais, as negociaçōes coletivas antes realizadas por categorias de trabalhadores passam a se basear em normas e regras que, mesmo pactuadas coletivamente, aplicam-se individualmente. A dimensão que se sobressai nesse contexto é a experimental. A competência expressaria coerentemente essa dimensão, pois, sendo uma noção originária da psicologia, ela chamaria a atenção para os atributos subjetivos mobilizados no trabalho, sob a forma de capacidades cognitivas, sócio afetivas e psicomotoras (RAMOS, 2002, p. 402). 
As principais reformas ocorridas no sistema educativo brasileiro na década de 1990 alinharam formação de força de trabalho aos imperativos da fase de acumulação flexível do capital, conduzida pelo capital internacional, representada pelos organismos internacional e localmente por representantes dos empresários. Essa ótica decorre de um modelo de Estado em que a hegemonia da classe dominante se torna presente nas políticas públicas, pois quando a sociedade civil elege seus representantes, eles passam a compor a sociedade política, que passa a dominar o aparato jurídico e coercitivo do Estado. É o que forma o Estado ampliado teorizado por Gramsci (1987).

No âmbito da política pública, esse investimento na qualificação do homem para o trabalho se dá por meio da educação profissional. Frigotto (2001) afirma que a valorização da educação profissional pelo governo vem sendo apontada, mais uma vez, como a melhor possibilidade de alinhar o Brasil à nova ordem mundial. Porém, não há espaço para todos, mas apenas àqueles que desenvolvem competências reconhecidas pelo mercado, para garantir não mais apenas o posto de trabalho e ascensão numa determinada carreira, mas a empregabilidade.

Com relaçáo ao significado da noção ampliada de trabalho, teorizada por Marx (1971), torna-se importante saber que "a expansão do trabalho em serviços, em esferas não diretamente produtivas, mas que muitas vezes desempenham atividades imbricadas com o trabalho produtivo, mostra-se como outra característica importante da noção ampliada de trabalho." (ANTUNES, 2006, p. 12). Na visão de Saviani (1996, p. 152), trabalho é "[...] o ato de agir sobre a natureza, adaptando-a as necessidades humanas." A partir dessa definição, é possível perceber o trabalho como essência humana, mostrando que para o homem continuar existindo a necessita de produzir sua própria existência pelo seu trabalho, fazendo com que sua vida seja determinada pelo modo que sua existência é produzida.

Antunes (2006) faz um diagnóstico do que vem acontecendo nas relações de produção no mundo contemporâneo, afirmando que:

[...] o que vem ocorrendo no mundo contemporâneo é uma maior inter-relação, maior interpenetração, entre as atividades produtivas $\mathrm{e}$ as improdutivas, entre as atividades fabris e de serviços, entre atividades laborativas e atividades de concepção, que se expandem no contexto da reestruturação produtiva do capital. Uma concepção ampliada de trabalho nos possibilita entender o papel que ele exerce na sociabilidade contemporânea, neste limiar do século que se inicia. (ANTUNES, 2006, p. 13). 
O entendimento acerca do conceito de trabalho de Antunes (2006) e Saviani (1996) tem origem no conceito desenvolvido por Marx, em O Capital, onde afirma que:

Antes de tudo, o trabalho é um processo de que participam o homem e a natureza, processo em que o ser humano, com sua própria ação, impulsiona, regula e controla seu intercâmbio material com a natureza. Defronta-se com a natureza como uma de suas forças. Póe em movimento as forças naturais de seu corpo - braços e pernas, cabeça e mãos -, a fim de apropriar-se dos recursos da natureza, imprimindo-lhes força útil à vida humana. Atuando assim sobre a natureza externa e modificando-a, ao mesmo tempo modifica a sua própria natureza. (MARX, 1971, p. 211).

O interesse da esfera privada em ter o Estado como aliado para promover a qualificação dos jovens, adaptando-os ao mundo do trabalho nessa fase de acumulação flexível do capital, se efetua por meio das políticas do Estado educador, teorizado por Gramsci (1991), o qual tem por finalidade "adequar a 'civilização' e a moralidade das mais amplas massas populares às necessidades de desenvolvimento continuado do aparelho econômico de produção, portanto, elaborar também fisicamente tipos novos de humanidade." (GRAMSCI, 1991, p. 91).

Sob esta ótica, Gramsci estabelece sua concepção de Estado, como "todo o complexo de atividades práticas e teóricas com as quais a classe dirigente justifica e mantém não só o seu domínio, mas consegue obter o consentimento ativo dos governados." (GRAMSCI, 1991, p. 91).

Para Ramos (2012), a sociedade civil presente apenas na estrutura econômica, ao estender sua atuação, passa a figurar na dimensão do Estado com a sociedade política e, essa última, com poder sobre os dispositivos jurídicos, passa a configurar o Estado stricto sensu ou governo. Assim "a concepção de estado então se amplia, juntamente com suas funçóes, que passam a ser hegemônicas revestidas de coerção e implica tanto a superestrutura política e jurídica, quanto a própria economia.' (RAMOS, 2012, p. 30).

No âmbito do Estado ampliado de Gramsci (1987), a sociedade política nacional, por meio do bloco hegemônico no poder, incorpora às Políticas de Educaçáo Profissional concepçóes hegemônicas baseadas no princípio de competências, defendidas como fundamental pelo Banco Mundial e CNI para melhor adaptar à formação de força de trabalho para o mercado de produção mais flexível. Assim, documentos como a LDBEN no 9.394/1996, os Parâmetros Curriculares Nacionais (1999) e as Diretrizes Curriculares Nacionais para o 
Ensino Médio e para a Educação Profissional (1999) foram pensados levando em consideração uma educação fundamentada no princípio das competências.

A importância da escola como aparato contra-hegemônico aos ideais capitalistas é defendida por Gramsci (1991), que nos afirma:

[...] a escola é o instrumento para elaborar a hegemonia pelos trabalhadores, então, a escola deve ser disputada na direçấo de uma "escola única inicial de cultura geral, humanista, formativa, que equilibre com equanimidade o desenvolvimento da capacidade de trabalhar manualmente (tecnicamente, industrialmente) e o desenvolvimento das capacidades de trabalho intelectual. (GRAMSCI, 1982, p. 118).

Essas políticas públicas voltadas à educação profissional tornaram-se elemento importante na dimensão política e ideológica, servindo de estratégia da luta de classes; assim, a política do Estado vem garantindo a manutenção das relações de produção e divisão social do trabalho nessa fase de acumulação flexível do capital.

\section{Considerações Finais}

Esta pesquisa limitou-se a apresentar e discutir as propostas e interesses do empresariado nacional e dos organismos internacionais na reforma da educação profissional brasileira na década de 1990.

Os documentos elencados ao longo do texto contribuíram para a materialização de mudanças no sistema educativo brasileiro, alinhando formação de força de trabalho aos imperativos da fase de acumulação flexível do capital, conduzida pelo capital internacional representado, sobretudo, pela criaçáo de um consenso via Banco Mundial e localmente pela CNI.

No Estado capitalista, o bloco no poder vem sendo determinante para a aceitação de demandas de organismos internacionais para formulação de políticas sociais que seguem os padrões do modelo capitalista de produção, destacadamente o Banco Mundial, assim como demandas dos representantes dos empresários nacionais, sobretudo a Confederação Nacional da Indústria.

No bojo da fase de acumulação flexível do capital, os padrões de formação para o mundo do trabalho se constituem com um forte viés de polivalência e adaptabilidade à evolução dos processos tecnológicos, influenciando a introdução de princípios, como o das competências nos currículos da educação básica brasileira, sobretudo na década 1990 . 
O que se percebe na Proposta do Banco Mundial de 1995 é que os países em desenvolvimento devem promover reformas em seus sistemas educativos, adaptando-o aos ditames dos princípios neoliberais hegemônicos, ficando a educação diminuída à lógica de mercado, sob pena de não favorecer o desenvolvimento social do país, e diminuição da pobreza por não aderir a um consenso global de produção flexível.

\section{Referências}

ANTUNES, R. Adeus ao trabalho? Ensaio sobre as metamorfoses e a centralidade no mundo do trabalho. 11. ed. São Paulo: Cortez, 2006.

BANCO MUNDIAL. Relatório sobre o desenvolvimento mundial. World Bank, 1990.

Bank, 1995.

Prioridades y Estratégias para la Educación. Washington: World

BRASIL. Lei no 9.394 de 20 de dezembro de 1996. Estabelece as diretrizes e bases da educação nacional. Brasília, 1996. Disponível em: <www.planalto.gov. br/ccivil_03?leis/9394.htm>. Acesso em: 22 maio 2015.

. Decreto no 2208 de 17 de abril de 1997. Regulamenta o art. 36 e os artigos 39 a 42 da Lei no 9394/96. Diário Oficial da Uniáo, 18 de abril de 1997, seção 1, p. 7760.

. Conselho Nacional de Educação. Parecer CNE/CEB no 15, de $1^{\circ}$ de junho de 1998. Trata das Diretrizes Curriculares Nacionais para o Ensino Médio. Brasília: 1998.

. Conselho Nacional de Educaçáo. Parecer CNE/CEB no 16, de 5 de outubro de 1999. Trata das Diretrizes Curriculares Nacionais para a Educação Profissional Técnica de Nível Médio. Brasília: 1999.

BREMER, M. A. S. KUENZER, A. Z. Ensino médio integrado: uma história de contradiçôes. In: Anais do IX Seminário de Pesquisa em Educação da Regiáo Sul - ANPED SUL. Caxias do Sul/Rio Grande do SUL, 2012. Disponível em: <http://www.portalanpedsul.com.br/admin/uploads/2012/Trabalho_e_Educacao/ Trabalho/05_01_24_2217-6580-1-PB.pdf> Acesso em: 20 de dez. 2015.

CIAVATTA, M.; RAMOS, M. A “era das diretrizes”: a disputa pelo projeto de educação dos mais pobres. Revista Brasileira de Educaçáo, v. 17, n. 49, jan./abr. 2012. 
CONFEDERAÇÁO NACIONAL DA INDÚSTRIA. Educaçáo básica e formaçáo profissional: uma visão dos empresários. Rio de Janeiro, CNI, 1993.

CONFERÊNCIA Mundial de Educação para Todos. Declaração Mundial de Educaçáo para Todos. Plano de Ação para Satisfazer as Necessidades Básicas de Aprendizagem. Brasília, DF: UNIFEC, 1990.

DEITOS. Maria Lúcia de Melo. A formação do trabalhador num contexto de permanente mudança tecnológica. In: FIGUEREDO. I. M. Z.; ZANARDINI. I. M. S.; DEITOS. R. A. (Org.). Educaçáo, Política Social e Estado no Brasil. Cascavel: EDUNIOESTE; Curitiba: Fundação Araucária, 2008.

DELORS, J. Educação: um tesouro a descobrir. Relatório para a UNESCO da Comissão Internacional sobre Educação para o século XXI. São Paulo: Cortez; Brasília, DF: MEC: UNESCO, 1998.

FRIGOTTO, Gaudêncio. A produtividade da escola improdutiva. São Paulo: Cortez, 1984.

. Educaçáo e Crise do Capitalismo Real. 5. ed. São Paulo: Cortez, 2003.

Globalização e Crise do Emprego: Mistificaçóes e Perspectivas da Formaçáo Técnico-Profissional. Boletim Técnico do SENAC DN v. 2, n. 25, 2001.

. Concepçóes e Mudanças no Mundo do Trabalho e o Ensino Médio. Centro de Educação Tecnológica do Estado da Bahia, Bahia, 2008.

FRIGOTTO, G.; CIAVATTA, M.; RAMOS, M. N. A política de educação profissional no Governo Lula: um percurso histórico controvertido. Educaçáo \& Sociedade, Campinas, v. 26, n. 92, p. 1087-1113, out. 2005.

FRIGOTTO, Gaudêncio. CIAVATTA, Maria. RAMOS, Marise (Org.) Ensino médio integrado: concepções e contradiçôes. 3. ed. São Paulo: Cortez, 2012.

GRAMSCI, Antonio. Os intelectuais e a organizaçáo da cultura. Rio de Janeiro: Civilização Brasileira, 1991.

. Cartas do cárcere. 3. ed. Tradução de Noênio Spínola. Rio de Janeiro: Civilização Brasileira, 1987.

. Cadernos do cárcere. Rio de Janeiro: Civilização Brasileira, 2002, v. 5.

. Cadernos do Cárcere. Os intelectuais, O princípio educativo. v. 2, Rio de Janeiro: Civilização Brasileira, 2010. 
. Cadernos do Cárcere. V. 1. Introdução ao Estudo da Fisolofia. A filosofia de Benedetto Croce. v. 1, 7. ed. Rio de Janeiro: Civilização Brasileira, 2014. HARVEY, D. A condição pós-moderna. 6. ed. São Paulo: Edições Loyola, 1992. IGNÁCIO, Paulo César de. A acumulação flexível no Brasil e suas demandas de qualificação da força de trabalho. In: BATISTA, Eraldo Leme; MULLER, Meire Terezinha (Org.) Realidades da Educaçáo Profissional no Brasil. São Paulo: Ícone, 2015.

KUENZER, A. Z. A educação profissional nos anos 2000: a dimensão subordinada das políticas de inclusão. Educ. Soc., Campinas, v. 27, n. 96 - Especial, p. 877-910, out. 2006.

MARX, Karl. O Capital, Rio de Janeiro: Civilização Brasileira, Livro I, v. 1. 1971. . Crítica da filosofia do direito de Hegel. São Paulo: Boitempo, 2010

MARX, K.; ENGELS, F. A ideologia alemã. São Paulo: Boitempo, 2007.

MELO, Alessandro de. O projeto pedagógico da Confederaçáo Nacional da Indústria para a educaçáo básica nos anos 2000. Tese (Doutorado) - Universidade Federal do Paraná, Programa de Pós-Graduação em Educação, Curitiba, 2010.

OLIVEIRA, Dalila Andrade. O ensino médio no contexto das políticas para a educação básica. In: ZIBAS, Dagmar; AGUIAR, Márcia; BUENO, Maria. O ensino médio e a reforma da educaçáo básica . Brasília DF: Plano Editora, 2002. p. 47-69.

PAIVA, Vanilda. Produçáo e qualificação para o trabalho: uma revisão da bibliografia internacional. Textos de discussão do Instituto de Economia Industrial. Textos n. 216. Rio de Janeiro: IEI/UFRJ, 1989.

RAMOS, M. N. A Pedagogia das Competências: autonomia ou adaptação? 2. ed. São Paulo: Cortez, 2002.

RAMOS, Marise N. Possibilidades e Desafios na Organização do Currículo Integrado. In: RAMOS, Marise N.; FRIGOTTO, Gaudêncio; CIAVATTA, Maria. Ensino Médio Integrado: Concepção e Contradiçôes. São Paulo: Cortez, 2012, p. 106-127.

SADRI, Simone. Parâmetros Curriculares Nacionais Para o Ensino Médio e a Relação Tecnologia e Educação. In: FIGUEREDO. I. M. Z.; ZANARDINI. I. M. S.; DEITOS. R. A. (Orgs). Educação, Política Social e Estado no Brasil. Cascavel: EDUNIOESTE; Curitiba: Fundação Araucária, 2008. 
SAVIANI, Demerval. O Trabalho como Princípio Educativo Frente às Novas Tecnologias. In: FERRETTI, C. J. et al., (Org.). Novas Tecnologias, Trabalho e Educação: um debate multidisciplinar Rio de Janeiro: Vozes, 1996.

SAVIANI, Dermeval. O choque teórico da politecnia. Trabalho, educaçáo e saúde, v. 1, n. 1, p. 131-152, 2003.

SHIROMA, Eneida Oto; MORAES, Maria Célia Marcondes de; EVANGELISTA, Olinda. (Org.). Política educacional. Rio de Janeiro: Lamparina, 2002.

TORRES, Rosa María. Melhorar a qualidade da educação básica? As estratégias do Banco Mundial. In: TOMMASI, L. de; WARDE, J. M.; HADDAD, S. (Org.) O Banco Mundial e as políticas educacionais. São Paulo: Cortez/Ação EducativaPUC-SP, 1997. 